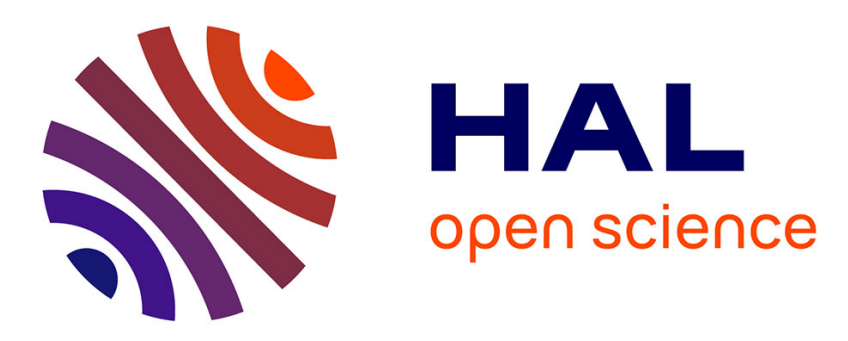

\title{
RFID interactive tabletop application with tangible objects: exploratory study to observe young children' behaviors
}

\author{
Sébastien Kubicki, Marion Wolff, Sophie Lepreux, Christophe Kolski
}

\section{- To cite this version:}

Sébastien Kubicki, Marion Wolff, Sophie Lepreux, Christophe Kolski. RFID interactive tabletop application with tangible objects: exploratory study to observe young children' behaviors. Personal and Ubiquitous Computing, 2015, 19 (8), pp.1259-1274. 10.1007/s00779-015-0891-7 . hal-01264366

\section{HAL Id: hal-01264366 \\ https://hal.science/hal-01264366}

Submitted on 29 Jan 2016

HAL is a multi-disciplinary open access archive for the deposit and dissemination of scientific research documents, whether they are published or not. The documents may come from teaching and research institutions in France or abroad, or from public or private research centers.
L'archive ouverte pluridisciplinaire HAL, est destinée au dépôt et à la diffusion de documents scientifiques de niveau recherche, publiés ou non, émanant des établissements d'enseignement et de recherche français ou étrangers, des laboratoires publics ou privés. 


\title{
RFID interactive tabletop application with tangible- objects: exploratory study to observe young children' behaviors
}

\author{
Sébastien Kubicki ${ }^{a}$, Marion Wolff ${ }^{b, c}$, Sophie Lepreux ${ }^{\mathrm{d}, \mathrm{e}}$, Christophe Kolski ${ }^{\mathrm{d}, \mathrm{e}}$ \\ ${ }^{a}$ ENI Brest, UMR 6285, Lab-STICC, F-29200 Brest, France \\ ${ }^{b}$ Université Paris Descartes, 75270 Paris Cedex 06, France \\ ${ }^{c}$ ESTIA/PEPSS, 64210 Bidart, France \\ ${ }^{d}$ UVHC, LAMIH, F-59313 Valenciennes, France \\ ${ }^{e}$ CNRS, UMR 8201, F-59313 Valenciennes, France
}

\begin{abstract}
Numerous academic and industrial studies and developments concerning interactive tabletops are paving the way for new educational applications. We have developed an interactive tabletop application equipped with RFID technology. This tabletop, called TangiSense, is based on a Multi-Agent System that allows users to associate information with behaviors to manipulate tangible objects. The application involves the recognition of basic colors. With the application, children are required to manipulate tangible objects. Their task involves recognizing objects that have "lost" their dominant color and placing these objects in appropriate colored areas. A tangible magician object automatically analyzes the filled zones and provides children and their teacher with virtual and vocal feedback. This application has been evaluated in a field study with children 3 to 5 years of age. The initial results are promising and show that such an application can support interaction and collaboration, and subsequently educational situations, among young children.
\end{abstract}

Keywords: Tabletop interaction; Virtual and Tangible Objects; Exploratory study Children; RFID

\section{Introduction}

The work presented in this article is based on reports that computers are being used in schools with increasing frequency. Today, we no longer find simple calculators in the classrooms; we have already moved on to the era of computers and interactive whiteboards, even tablets. In recent years in France, for example, certain schools known as "smart schools" have been providing education with a computer for each child [51]. For several years now, the same approach has been observed in many other countries in Europe, the United States and other countries [26][33][38].

This new technical equipment has made it possible to provide schools and teachers with new ways of teaching, and thus, to provide children with new ways of learning. However, now that computers have been integrated into schools, research is already focusing on a very different interactive platform: the interactive tabletop ( $c f$. the growing interest in new conferences, such as ACM ITS "Interactive Tabletops and Surfaces" Conferences from 2009 to the present).

The interest in using tables in education (in a general way) is not new. For example, the work of Thomson et al. [67], Ampofo et al. [3] and Fyhri et al. [25] have shown that the table (i.e., a standard and non interactive tabletop) is a good way to recreate the real environment and expose children to traffic situations of interest; Fyhri et al. use the table concept (e.g., a model with objects representing road traffic) to raise children's awareness of road traffic problems.

Over the years, Human-Computer Interaction $(\mathrm{HCI})$ research has contributed to the emergence of new technologies such as smartphones, tablets, and interactive tabletops. Like standard tables, researchers believe that interactive tabletops can be very useful tools in the educational world. Interactive tabletops have a large interaction surface area and offer new ways for users to interact with a digital world (i.e. via "tactile", "multitouch", or "tangible" interfaces). Furthermore, according to Ishii and Ulmer [35], tangible user interfaces "augment the real physical world by coupling digital information to everyday physical objects and 
environments" (p.236). Ishii and Colleagues advise a tight coupling of control of the physical object and the manipulation of its digital representation [36][35] to design a useful and friendly TUI. Fishkin [24] proposed taxonomy for tangible interfaces. These interfaces allow "the user to uses their hands to manipulate some physical object(s) via physical gestures, a computer system detect this, alters its state and gives feedback accordingly". Zaman et al., [76] focus on the impact of tangibility in terms of usability, learning, collaboration, and fun. Marshall [50] identifies 'Effects of Physicality' as one of six themes in an analytical framework to guide research and development of tangibles for learning. From the observation that manipulatives and physical learning materials are prevalent in educational settings across cultures, Manches and O'Malley indicate possible limitations of physical objects - most importantly that their symbolic significance is only granted by the context in which they are used [48]. Tangible interactions through metaphors make such learning devices particularly interesting [5].

However, to interact with a tangible interface (Tangible User Interface, TUI) does not imply the same situations of use than a classical graphic interface (Graphical User Interface, GUI). Many research showed the advantages of TUIs like, for example, to live a more natural and user-friendly [36] and/or intuitive experience [22]. In [65], they conclude that the tangible interface was capable of promoting a stronger and long-lasting involvement having a greater potential to engage children. In [58], they compare the using of TUI versus GUI to program a robot. The comparison involved three dependent variables, namely first-sight preference (attractiveness), enjoyment and easiness-to-use. The conclusion depends on the age and gender of the children. The literature review suggested by Zuckerman and Gall-OZ [77] aim at proposing an in-depth analysis of the advantages and weaknesses of TUIs vs. GUIs. On another side, research showed the interest of the handling and use of objects for children training [1]. Finally, the pedagogical values of object manipulation have been promoted by Montessori [14]: "Children build their mental image of the world, through the action and motor responses; and, with physical handling, they become conscious of reality".

In section 2 of this article, we propose to introduce interactive tabletops and their specificities and present several educational and interactive tabletop applications mentioned in the literature. Section 3 introduces the TangiSense interactive tabletop, the medium resulting from our work, which enables tangible interactions to take place; we also describe our proposal for an application with an educational objective. The protocol used to evaluate the medium in the field (a classroom) is presented in section 4. The analyses resulting from the questionnaires and videos are presented in section 5. The article ends with a discussion, a conclusion and suggestions for future research.

\section{Interactive tabletop: a new learning medium at school?}

During the last ten years, several researchers have utilized interactive tabletops as learning medium. Different questions have been studied and the main one has been whether the interactions supported by interactive tabletops may enhance user collaboration.
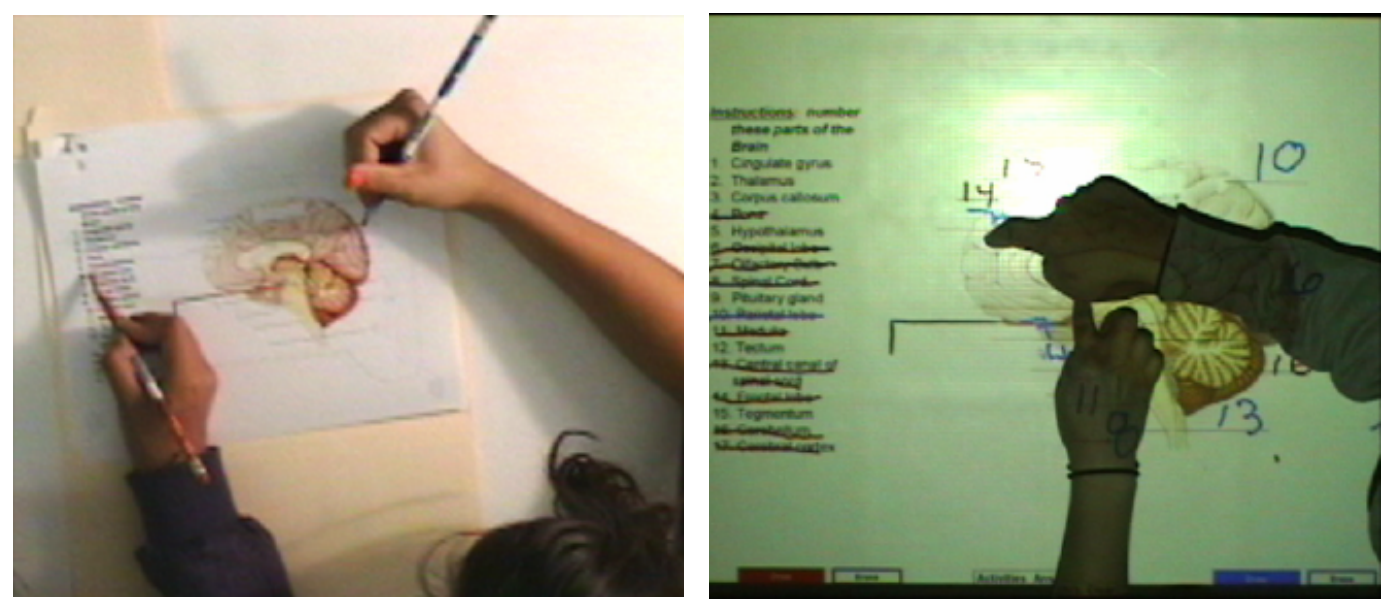

Figure 1 The two modes of revision used by students in [54]: (left) student labels items on the paper diagram while partner crosses off items; (right) both students label digital diagram at the same time. 
Piper et al. [54] proposed a study on the effect of a multi-touch tabletop in a small group collaborative learning setting for a neuroscience class at UCSD demonstrated that the multi-touch tabletop encourages students to experiment more with problem solutions (cf. Figure 1). Kelly et al. [37] developed an application (called Solar Scramble) on a multi-touch interactive tabletop aimed at 5 to 10 year olds. The game's objective was to teach the placement of the planets in the solar system. The game's evaluation by five child education experts revealed the potential of interactive tabletops for multi-user interactions by supporting the children's collaborative activities. Harris et al. [28] has also studied the use of multi-touch interactive tabletops for collaborative child learning. 45 children (21 boys, 24 girls) aged from 7-10 took part in a classroom study where they manipulated digital objects on an interactive tabletop. The results showed that the children's participation was significantly higher when utilizing a multi-touch method instead of single-touch. In other words, multi-touch encourages collaborative interaction. These studies have influenced some research supported by these new technologies in the learning domain [69][68]. A recent literature review [31] showed that interactive tabletops could significantly benefit collaborative training. Since tabletops are naturally viewed as learning media, additional environments, such as the Collaid (Collaborative Learning Aid) environment, are proposed in order to, for example, capture the generated traces (who says what? who does what?) during collaborative interactions in a learning context [52].

On the other hand, there are clear educational advantages to associating interactive tabletops with tangible objects. For instance the read-it application proposed by Sluis et al. [61] showed that the \{tabletop, tangible \} couple was interesting in teaching children age 7 to 9 years how to read. This application provides a dedicated area of the tabletop's edge for each child and a common area in the center. The issue of display orientation is addressed and some guidelines are provided by Kruger and colleagues [39]. Marco et al. [49] with the NIKVision tabletop propose a farm game dedicated to (3-6 years old). In this application, only one child manipulates the tangible objects. They estimated the degree of fun and engagement from video. They conclude that the combination of both outputs (tabletop and 3D animations displayed on another screens put on the tabletop) have a success. In this case, we cannot deduce if the tangible or the 3D animations or both bring the success. Another application that uses an interactive tabletop was proposed by Do-Leng et al. [21]. This tabletop involves interactions with paper (tangible). This tabletop works both as an input device and a visual feedback display for users; hence, it enables users to engage in natural and direct interaction. This article aims to show this technique's benefit in collaborative learning tasks compared with the use of a computer positioned between three interacting subjects.

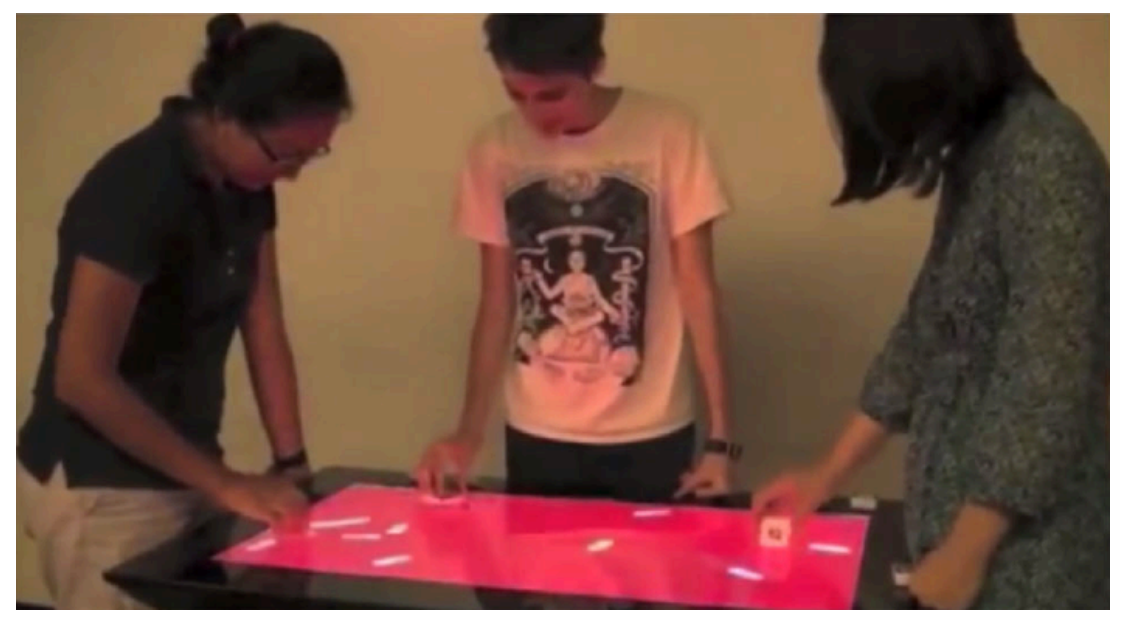

\section{Figure 2 Students using SynFlo on a Microsoft PixelSense interactive tabletop [60]}

More recently, Bonnard et al. [12] investigated how a serious game for geometry training with tangible interactions could help 10 to 12 year old children. Shaer et al., proposed the G-Nome Surfer application [59] which can be used on an interactive multi-touch and tangible tabletop. It helps teenagers (undergraduate students) learn biology (genomics in cases where abstract information is represented). A study was conducted to show the benefits of interactive tabletops in the learning process compared with traditional graphical user interfaces (GUIs) or a multi-mouse GUI (bimanual interaction involving multiple users in integrated workflow on a vertical surface). Later, Shaer et al., [60] proposed design considerations and participatory design process 
for enhancing college-level science education through reality-based interaction by using SynFlo (an interactive installation for illustrating core concepts of synthetic biology for non-scientists) on a Microsoft PixelSense interactive tabletop and tangible objects ( $c f$. Figure 2).

The contribution of tangible interaction to learning in children was demonstrated by [78][63][34] and seems to be an interesting educational method. Furthermore, some of the claims made seemed to stretch existing findings or arguments. For example, the paper by Marshall [50] is used to suggest that the contribution of tangible interaction to learning has been demonstrated, but actually it makes exactly the opposite point, that there has been little empirical. Xie et al., demonstrated that children (aged 7-9 years) experience more enjoyment when using a tangible medium on a tabletop in a learning context (e.g., collaborative jigsaw puzzles) [74]. Of course, the proposed task must be adapted to these interaction modalities, as mentioned by Lucchi et al. During this study, they concluded that tactile tabletops are more easily generalized to a wide variety of applications and are easier to design. However, they also concluded that tabletops are less intuitive because of a lack of familiarity with them (meaning that training on tabletop use is required) and the fact that they do not achieve persistence and only provide visual feedback. In contrast, tangible tables pertain to a specific application purpose, have a challenging design, are generally more efficient and faster to use, induce persistence (i.e., "One strength of the tangible objects is to exist outside the space defined by the projection screen. Conversely, the non-persistence of virtual objects allows them to be decoupled from the real world where physical laws apply.") and provide visual, tactile and audio feedback [47].

Despite these cited works, this research field is still a young one. There is a lack of empirical data located in real situations (such as in a classroom setting). This makes it difficult to offer conclusive evidence on the effectiveness of interactive tabletops as new learning medium at school [31]. Our work is aimed at supplying more data on this question by focusing on the classroom environment. Given this research, we would like to propose a tabletop platform with tangible (not tactile) interaction as a medium to encourage interaction and collaboration among children.

\section{New type of educational application that exploits tangible objects on an interactive tabletop}

The previous section demonstrated some research studies that involve tactile interactive tables used for learning purposes. Some other studies demonstrating the benefits of tangibility in interaction and learning have led us to propose (1) a tangible interactive tabletop, which is presented in first section and (2) an educational application to help children recognize and learn colors, which is presented in the second section.

\section{Interaction medium: the TangiSense interactive tabletop}

The TangiSense interactive tabletop (cf. Figure 3) promotes interaction with virtual objects (using LEDs or an overhead video projector and sound feedback) as well as with tangible objects. The interactions with the latter are made possible thanks to the technology used: RFID [23] (Radio Frequency IDentification). The use of RFID makes it possible to detect objects present on the surface of the tabletop (thanks to the tabletop's different RFID antennas, which detect RFID tags), to identify them through one or more tags underneath the object (since an RFID tag is unique), and to store information directly in these objects or to superimpose data on them. It is thus possible to work with a set of objects on a tabletop, to store data in these objects (e.g., their last position) and to be able to re-use the data on another tabletop at another time with the user's own embedded information (e.g., the last move of a game of chess). Designed by RFIdées ${ }^{1}$ Company, the tabletop is made up of $2.5 \mathrm{~cm}^{2}$ "tiles", each containing 64 antennas $(8 \times 8)$ on a surface of $1 \mathrm{~m} * 1 \mathrm{~m}$. Each tile contains a DSP processor, which reads the RFID antennas, the antenna multiplexer, and the communication processor. The tabletop contains 25 "tiles" ( 5 x 5), or 1,600 antennas in total, so the tabletop can arrange 1,600 objects ( $c f$. Figure 3 ).

\footnotetext{
${ }^{1}$ http://www.rfidees.fr/
} 

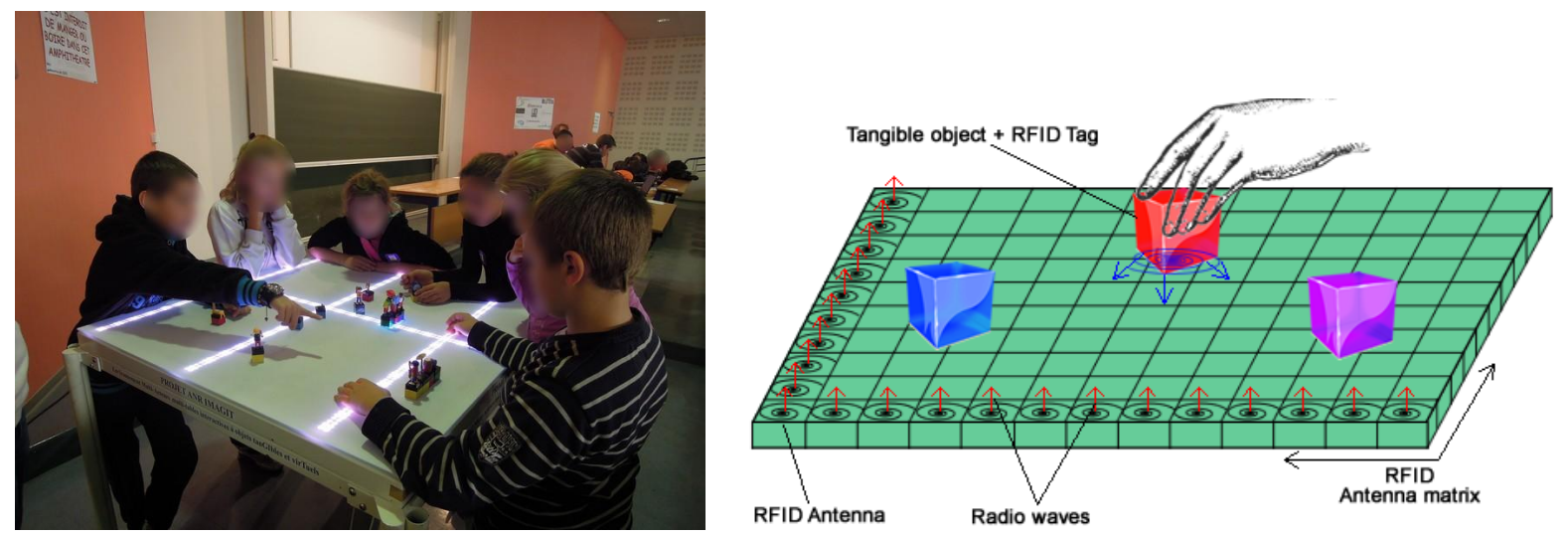

Figure 3 (Left) Some pupils using the music creation application [4] on TangiSense [43] and (right) the RFID system

Each antenna contains four RGB LEDs (prototype v4), which enable users to interact by displaying / lighting some virtual objects, with very low resolution of course. The tiles are linked to a control interface connected to the host computer through an Ethernet link.

The selected software architecture includes several layers [43]:

- The hardware provides the unprocessed RFID tag information, which is detected.

- From information provided by the hardware layer, the middleware detects the tangible objects and processes events associated with the objects. This layer communicates object position modifications to the MultiAgent System.

- The Multi-Agent System (MAS) layer provides the system with reasoning capacities. It was developed with the JADE platform [9][46][41]. The MAS has a comprehensive view of the virtual and tangible objects that make up its environment.

- The Human-Computer Interaction (HCI) layer communicates with users and allows virtual information to be transmitted (e.g., the user's movement of a virtual object).

\section{Presentation of the color recognition application for the TangiSense interactive tabletop}

We developed a TangiSense interactive tabletop application for childhood learning (in compliance with France's teaching curriculum for preschools). We asked preschool teachers how an interactive tabletop and tangible objects could help them in their teaching. It was quickly determined that the entertainment aspect of interactive tabletops could be an attractive tool for children's learning in many areas (error management, group work, realistic situations with objects) and as a complement to paper and glue (cf. Figure 4)

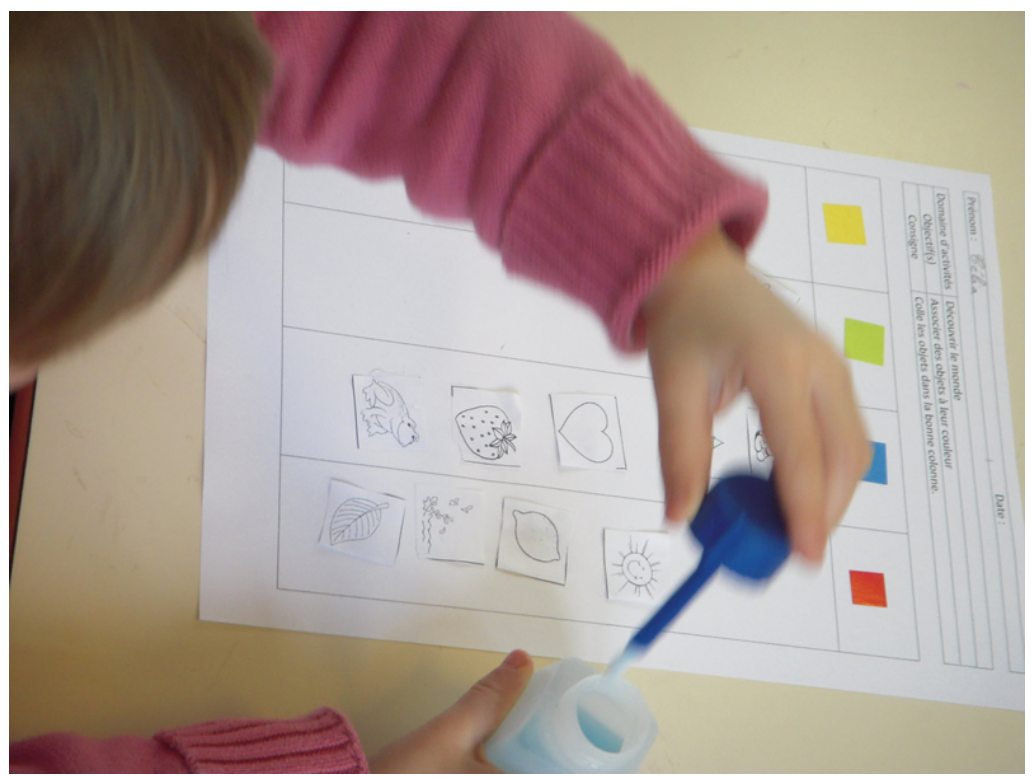

Figure 4 Use of paper, glue and colored stickers by preschool children to learn colors 
We subsequently asked a teacher to imagine one or more scenarios using an interactive tabletop and a set of objects, without any limits or constraints. The teacher proposed a simple application, in which children must put a set of objects that "lost their color" into the appropriate color box. For example, a colorless image of a banana would need to be placed into the yellow box. We proposed color recognition software developed for the TangiSense interactive tabletop and appropriate for children aged 2 to 5 years. Different scenarios were developed according to the learning level of a French preschool.

The selected method was as follows. Each child has a set of tangible objects (small cubes, each with a black and white image) [42]. The child was required to determine what the image represents, establish the image's appropriate color and place the object in the corresponding color box on the interactive tabletop. Once the objects are placed, the child is invited by the teacher to verify his/her choices using a character in the form of a magician (tangible object), which the child places on the table (cf. Figure 8). The magician then "launches" the verification procedure and announces to the child whether he/she has made any errors or has given correct answers. The teacher also obtains the results of each child (on an individual results sheet) so that he/she can quickly assess each child's difficulties and adapt his/her teaching accordingly.

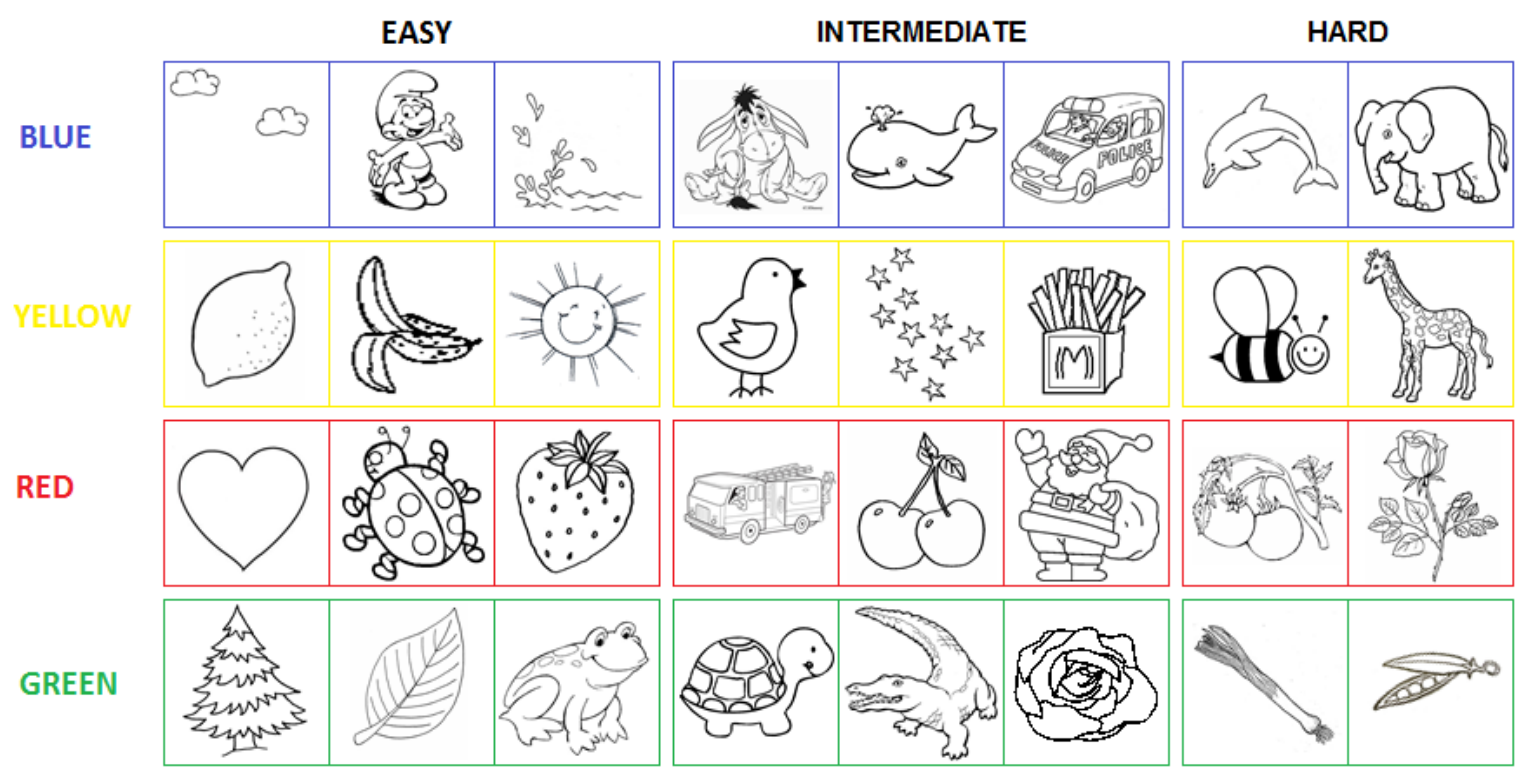

Figure 5 Listing of the images represented on the object "cubes"

Since the color recognition application mainly uses tangible objects, it was necessary to design the objects used for the application. We initially asked teachers to provide us with a set of images they were accustomed to using to teach children colors. It should be noted that, with the teacher, we decided to work only with red, green, blue and yellow, which are the colors taught to preschool children of all ages. It was the training scenarios, not the colors taught, that varied with children's level (preschool year).

The list of the images used and chosen by the teacher can be seen in Figure 5. Each color (blue, yellow, red and green) is thus represented by eight images. The objective was to propose eight objects of each color to be placed by the children. However, we realize that it is difficult to select eight different black and white objects representative of a single color, which is why some objects or figures may be considered ambiguous. However, these potentially ambiguous objects were generally well-known by the children (e.g. Eeyore, a character A. A. Milne's Winnie-the-Pooh books shown in blue in the Walt Disney movie version). 


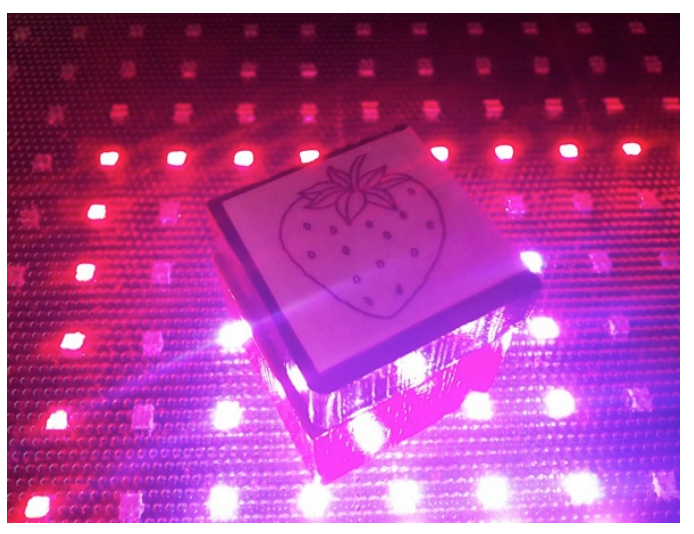

Figure 6 Example of a tangible object designed for the color recognition; application: a strawberry to be placed inside the red frame

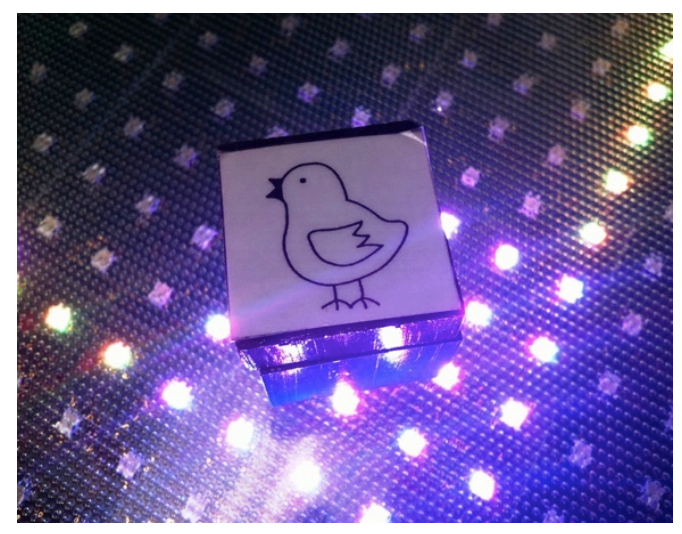

Figure 7 A chick to be placed into the yellow frame

Once the images were defined, we decided to design our own objects for this application. To do this, we chose to use small wooden cubes that could be easily manipulated by the children; it should be noted that learning about objects, materials and shapes is also part of the French preschool curriculum ${ }^{2}$. Each object had a painted base (so that each child could distinguish his/her cubes by color) and a black 'top' containing the image to be placed in the proper colored box. Figure 6 and Figure 7 show an example of two objects specially designed for the color recognition application and adapted to preschool children. It should be noted that these objects can be seen as passive because they do not play a particular role and do not trigger, for example, a table action. However, the tabletop's detection of each object is seen by the users as a luminous white halo under the object when this one is correctly identified.

Finally, the color recognition application uses a particular object called a magician. In contrast with objects that "lost their color", this object can be regarded as active. When the magician object is placed on the TangiSense interactive tabletop, this launches the verification procedure by scanning each object placed by a child and indicating correct placements and erroneous placements ( $c f$. Figure 8).

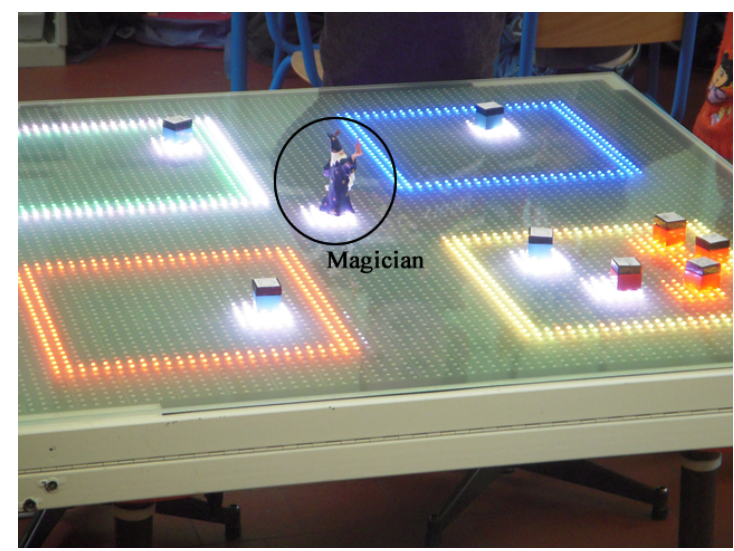

Figure 8 Placement of the magician on the interactive tabletop and verification by the magician of

\section{children's choices}

This object has a very important role. The children could be given their results in "real time" according to the position of the children's objects (e.g., if a child places a sun (yellow) within the red frame, the tabletop could immediately indicate to the child that this is incorrect by simply showing a red halo under the object and providing audio feedback that the object is incorrectly placed. However, using this method is problematic because the child will not focus on the objective of the task (i.e., defining the object, determining its color of origin and placing it in the proper place), but rather only on the goal of obtaining the correct answer. As a result, with this method, a child would place his/her object without thinking in different areas until the desired correct

\footnotetext{
${ }^{2}$ http://www.education.gouv.fr/cid33/la-presentation-des-programmes-a-l-ecole-maternelle.html
} 
answer is obtained. This is why we suggested using a tangible object representing a character (magician), to force children to think before correcting. Moreover, we will see further on that, in the end, it is the teacher who makes this decision. Teachers can ask a child questions, such as 'Are you sure that you are finished? Do you want to put the magician on the tabletop to check your answers?', which may encourage the child to re-examine his/her choices before placing the magician on the tabletop.

\section{Method}

The aim of this exploratory study presented in this article is to understand the contribution of TangiSense interactive tabletop as support and possible learning aids for young children and their teachers. Also through a collection of observations, we decided here:

- To study the behavior of children (interactions, manipulations...), who were confronted with color recognition tasks. These tasks were presented using two different tools for the same exercise: interactive tabletop and paper illustrations (stickers).

- To collect the teachers' opinion through a questionnaire containing open questions and attitude scales (Likert scales).

\section{Protocol}

Different color recognition scenarios were proposed for children aged 2 to 5 years. The children were required to use the color recognition application in the classroom in the presence and under the supervision of their teacher. The scenarios were developed according to the learning level of a French preschool. The objects used for this application were classified by three preschool teachers into three difficulty levels: easy, intermediate and hard. The classification for each color was provided by the teachers ( $c f$. Table 1$)^{3}$.

Table 1 Table representing the difficulty level associated with each object

\begin{tabular}{|c|c|c|c|}
\hline \multirow{2}{*}{ Object Color } & \multicolumn{3}{|c|}{ Difficulty Level } \\
\cline { 2 - 4 } & Easy & Intermediate & Hard \\
\hline Blue & Sky, Smurf, Sea & Eeyore (Winnie-the-Pooh), Whale, Police car & Dolphin, Elephant \\
\hline Yellow & Citron, Sun, Banana & Chick, Star, Fries & Bees, Giraffe \\
\hline Red & Heart, Ladybug, Strawberry & Fire truck, Cherry, Santa & Tomato, Rose \\
\hline Green & Christmas tree, Leaf, Frog & Turtle, Crocodile, Salad & Leek, Peas \\
\hline
\end{tabular}

\section{Scenario}

The tabletop was set up before the children's arrival, and thus before the experiment began. The teacher introduced the three analysts to the children and pointed out to the children that a tabletop has been added to their regular classroom ( $c f$. Figure 9)

\footnotetext{
3 For this "in the field" experiment, we will not consider the children's performance, since they are allowed to search for the right result alone or with the help of their teacher. Instead, only children's behaviors were studied to determine if an interactive game system can foster interaction and collaboration, and therefore encourage learning situations.
} 


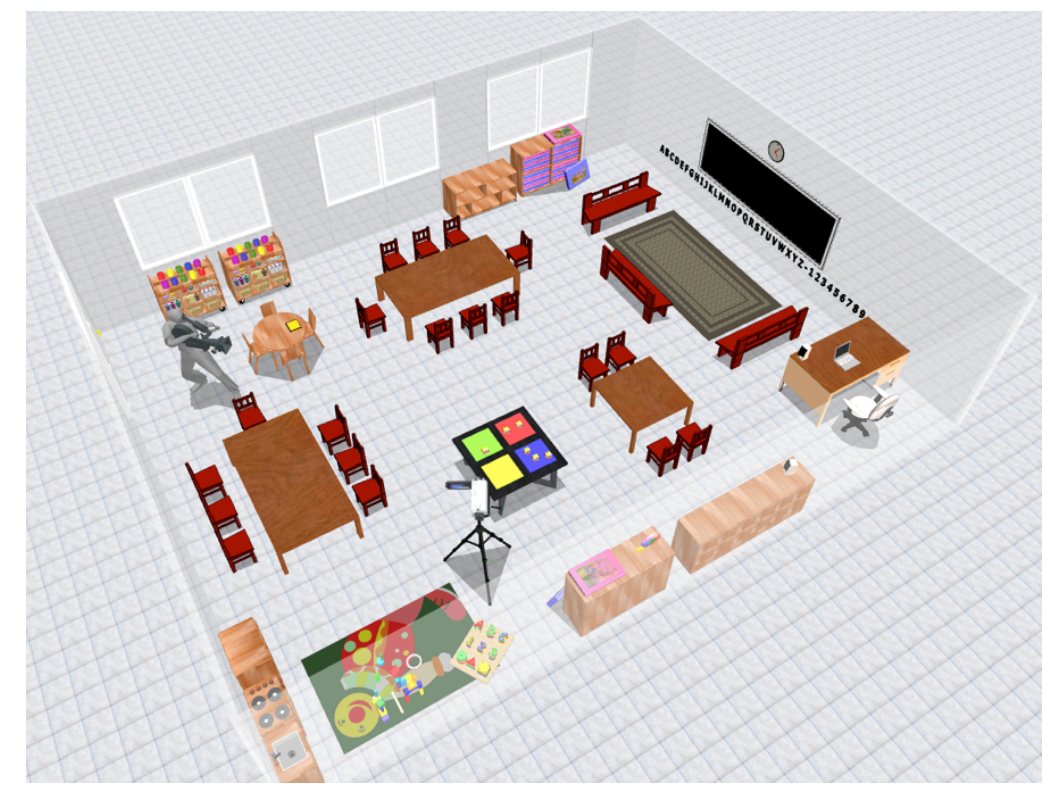

Figure 9. The interactive Tabletop TangiSense in the field context of a Classroom

After the introductions, the teacher showed the children the tabletop and explained the exercise. The implementation of this study, which was conducted in the field directly in the regular classroom) required authorization (from civil services, the head teacher, the pupil's teacher and parents). The obtained authorizations only enabled the experiment to be conducted for one day.

The experiment was required to be performed in between the usual daily activities to refrain from disturbing the pupils' usual schedule.

A Unified Modeling Language (UML) activity diagram places the activity relative to the tabletop exercise and the paper exercise for each participant group ( 7 interactive tabletop groups, 4 of which performed the exercise on paper as well) on the day in question (cf. Figure 10)

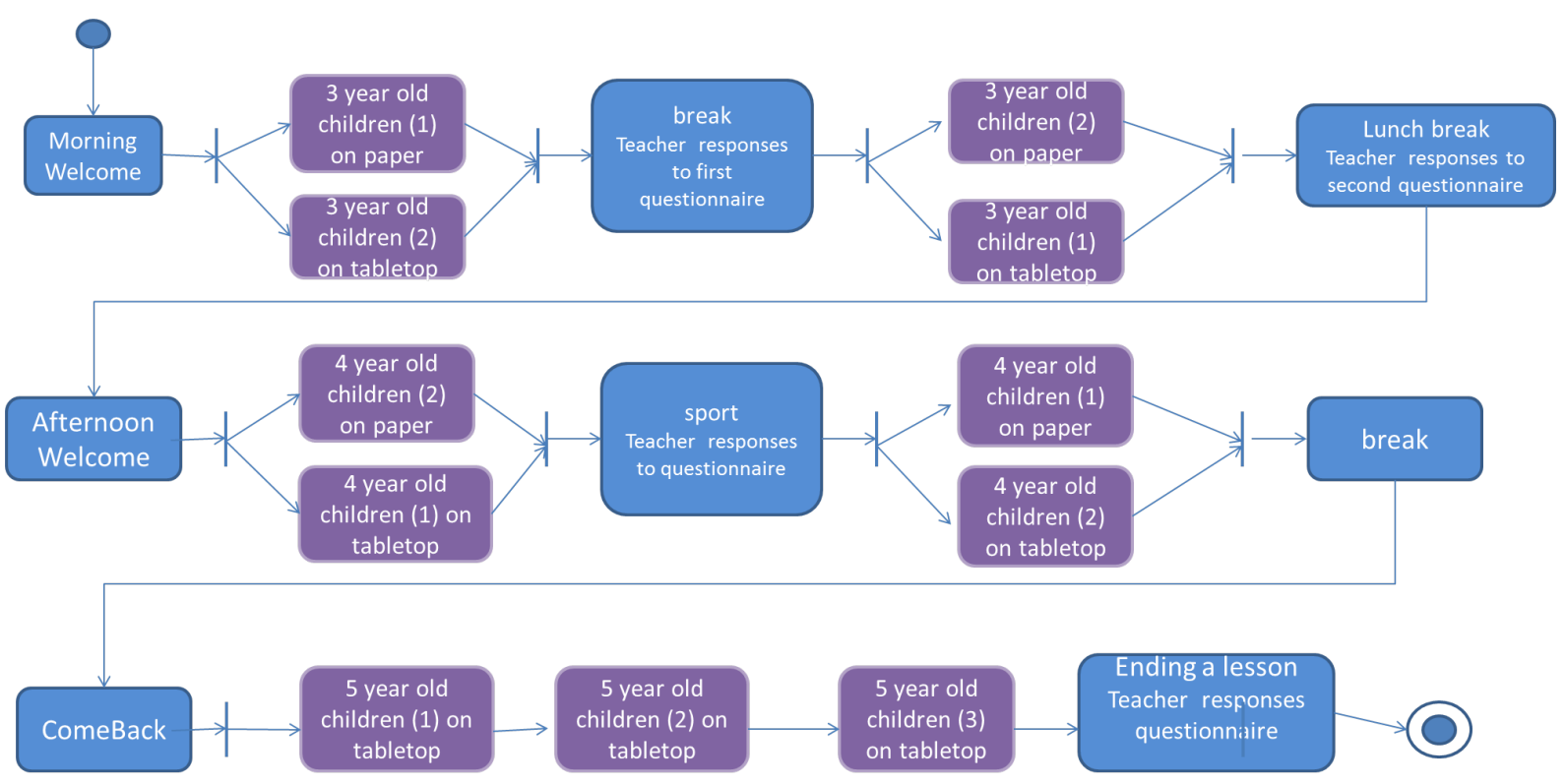

Figure 10 Activity of groups on experiment day in a field classroom context

Each child has a set of objects (small cubes each with a black and white image of the item in question; e.g., a lemon, a cherry or a Christmas tree). The child must recognize this item and then associate it with the appropriate color and place the object into the corresponding color box on the interactive tabletop. Once the objects are placed, the child is asked to confirm his/her choices using a tangible object in the form of a magician. The "magician" starts the verification process and indicates the child's errors or correct responses (cf. Figure 11 and Figure 12) 


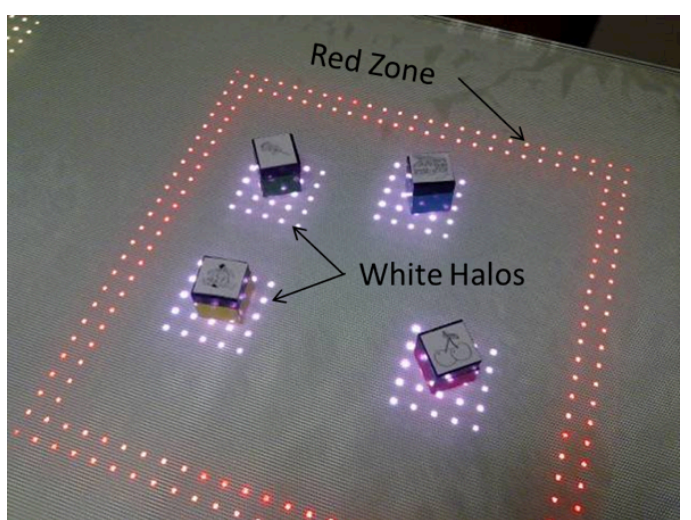

Figure 11 Four objects were placed in the red zone (the white halo under each object indicates that they have been detected by the tabletop)

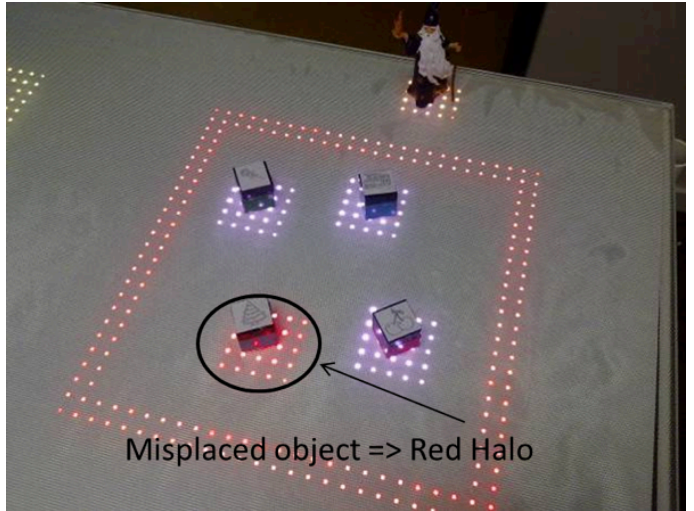

Figure 12 The "magician" detects that the "Christmas tree" object was not placed on the correct color (indicated by the red halo below the object and an associated vocal message, "Have you found all of the red objects? Oooh, you are wrong, try again.")

The protocol uses the following items: (1) the interactive TangiSense tabletop at a suitable height for children showing four areas of color (blue, red, green, yellow), (2) a set of 32 tangible objects that have "lost their color" to be placed in the correctly colored box (cf. Figure 11 and Figure 12), (3) the tangible 'magician' object (4) a paper version of the objects presented in four columns and packaged with colored stickers for the youngest children, (5) two cameras (one for filming the central tabletop area and one for providing a global view of the tabletop), and (6) teacher questionnaires with Likert scales (ranging from 1: strongly disagree to 10: strongly agree). It was also possible to provide comments to explain each given score.

\section{Participants}

This exploratory study was designed to determine whether or not an interactive exercise system would foster interaction and collaboration between children and between children and a teacher. It was conducted in a preschool in Caullery (in the Nord department in northern France.). Sixteen children aged 3 to 5 years in one of the three standard French preschool 'grades' (petite section, or children aged 3-4), (moyenne section, or children aged 4-5), and (grande section, or children aged 5-6) participated in this color recognition game, which had three levels of difficulty identified by teachers. For the first two groups (petite and moyenne section children), two situations were used: "interactive tabletop" and "stickers"; the stickers were used for the same purpose as the tabletop, but with colored stickers to be placed on a sheet of paper identify 'lost' colors. Each petite and moyenne section group was examined in both situations with an interval of approximately 30 minutes between situations. Each group could choose to start with either of these situations as they wished. However, grande section children were examined only in the "interactive tabletop" situation, since the teachers deemed the "stickers" situation to be too easy for these 5-to-6-year-olds. The groups were balanced in terms of gender. Sub-groups of smaller sizes were randomly created so that all children could participate and express themselves freely ( $c f$. Figure 10)

- Gr1: 5 children aged 3-4 years ( 3 boys and 2 girls) divided into 2 sub-groups $(n=2 \& n=3)$,

- Gr2: 5 children aged 4-5 years ( 2 boys and 3 girls) divided into 2 sub-groups $(n=2 \& n=3)$.

- 6 children aged 5-6 years ( 3 boys and 3 girls) divided into 3 sub-groups $(n=2)$.

Each group of children was accompanied either by a teacher (for the "interactive tabletop" situation) or by a teaching assistant specializing in preschools (for the "stickers" situation).

\section{Data collection procedure}

All exercise sequences around the interactive tabletop were videotaped for 15 minutes. The children's behaviors were videoed using an observation grid as it is classically developed in ergonomics. The behaviors were identified through a seven-step analysis [62]: 1) preliminary viewing, 2) choice and definition of classification units, 3) development of an initial category list, 4) reduction of the category list, 5) classification of the behaviors by two external coders who were blind to the aim of the study and subject group assignment, 6) consensual 
agreement in case of doubt, 7) analysis and interpretation. Mean intercoder reliability (number of agreements/number of agreements + number of disagreements) based on a random sample of $20 \%$ of observations was $90 \%$. The first viewing of the children's behaviors generated a wide variety of categories. After successive viewings, the researchers and the two coders agreed to combine the categories into three major behavior types: interaction, object manipulation, error processing. These types covered almost all behaviors.

Only the observations of the youngest groups (3-4 year-olds: Gr1) were analyzed for both situations ("interactive tabletop" and "stickers"). Videos could not be used for the "stickers" situation for 4-5 year-olds (Gr2), and the 56 year-olds (Gr3) were not placed in the 'stickers' situation because it was judged to be too easy for them. We defined "interaction" as all interactions in which the child participated (interactions between children, between children and the teacher or agent: gestures or verbal requests). "Object manipulation" reflects situations in which the child grasps the object to move it or to relocate it. Behaviors for which the teacher mentions an error, and more generally, for which the teacher or agent obliges the child to relocate the object or where the child realizes his/her error, were combined in the "error processing" category. When the behavior involving the teacher and the child did not occur, this was coded as "absent" and was not considered for analysis. This was the case for any behavior that did not really describe an error or was considered to be irrelevant. Therefore, for 4-5 and 5-6 yearolds, we did not obtain a relevant number of behaviors for the "error processing" category.

In order to identify different behaviors in the children, we followed an approach traditionally used to analyze categorical data [16][19][71][73]. The children's behaviors recorded during the observations were classified into distinct categories to obtain different contingency tables. For example, a contingency table (cf. Table 2) presents the distribution of the relative frequencies - percentages - (and observed counts) of the 67 children behaviors in the different categories for each age. For this cross-classified data tables, the global association test is carried out using the chi-square test ( $\mathrm{chi}^{2}$ test). In addition to this global association, we also studied local dependencies (local associations) within the contingency table to highlight the specific group of cells that was overrepresented or underrepresented. The analysis of these over-representations and under-representations was carried out with a specific index called the association rate [11], as presented in the next session.

\section{Results}

\section{Observations}

For all children, interaction was observed more often (weighted mean WM: 55\%) than object manipulation (WM about: $45 \%$ ), regardless of the children's age. We did not test the global association $\left(\chi^{2}\right.$ test) between these two categorical variables (Children's behavior x Children's age) on the basis of cross-classified data. Such a test would not be relevant here for various reasons. The first reason why such a test would be irrelevant is that the statistical conditions would not be met, especially since individual values and expected values are too scarce [29]. The second reason is that we are more interested in emphasizing the similarities (or differences) between the children's behaviors (as they appear through the observations) than knowing if the behaviors globally differ from each other. To this end, we studied the local dependencies (local associations) within a contingency table so as to highlight which specific group of cells is overrepresented or underrepresented. The analysis of these overrepresentations or under-representations is carried out with a specific index called the association rate [11][18][72]. Association rates are used in exploratory studies since they enable local associations within a set of data to be measured. For each cell of a contingency table, the association rate between modalities is defined as the comparison between the observed frequency and the expected frequency ${ }^{4}$. The sign of the association rate indicates whether there is an attraction $(+)$ or a repulsion $(-)$ between the modalities. The association rate can also be interpreted as an overrepresentation of a cell. For example ( $c f$. Table 2) the cell AR - Association Rate - [3-4

\footnotetext{
${ }^{4}$ Expected frequency is obtained by calculating the product of the corresponding marginal frequencies of value a (Variable A) and $\mathrm{b}$ (Variable B) for each cell of a contingency table. The expected frequency is defined as the product-frequency. In independent cases, the observed frequency is equal to the expected frequency. For each cell, the association rate is obtained by calculating the difference between the observed frequency and the expected frequency. This difference is then divided by the expected frequency. For full theoretical demonstrations, see Le Roux and Rouanet [45] or Corroyer and Wolff [18]
} 
year-old/Object manipulation $=+0.34$ ] indicates that the cell contains $34 \%$ more observations than it would have contained in the case of independence.

Table 2 Observed relative frequencies - \% - (observed counts) and observed Association Rates (AR) of children's behaviors according to their age\}

\begin{tabular}{|c|c|c|c|c|c|}
\cline { 2 - 6 } \multicolumn{1}{c|}{$\begin{array}{c}\text { Children's behavior }(\rightarrow) \\
\text { Age of the children }(\downarrow)\end{array}$} & \% (Counts) & $\boldsymbol{A R}$ & \% (Counts) & $\boldsymbol{A R}$ & Total \\
\cline { 2 - 6 } \multicolumn{1}{c|}{} & $40.00(8)$ & -0.28 & $60.00(12)$ & +0.34 & $100 \%(20)$ \\
\hline 3-4 year-old & $61.90(13)$ & +0.12 & $38.10(8)$ & -0.15 & $100 \%(21)$ \\
\hline 4-5 year-old & $61.54(16)$ & +0.14 & $38.46(10)$ & -0.14 & $100 \%(26)$ \\
\hline 5-6 year-old & \multicolumn{2}{|c|}{$55.00(37)$} & $45(30)$ & $100 \%(67)$ \\
\hline Weighted mean $(\mathrm{WM})$ & & & & \\
\hline
\end{tabular}

The rates shown with a positive sign indicate similarities between the variables of the cells while negative rates indicate disparities. Association rate analysis can be supplemented with a geometric analysis aimed at processing a correspondence analysis [45]. In this study, there were not enough available values to allow this method to be used. The more relevant association rates obtained in Table 2 reveal similarities in interactions between 4-5 yearolds and 5-6 year-olds. Thus, 3-4 year-old and 4-5 year-old children appear to interact more than 3-4 year-old children, who showed more interest in manipulating objects. These results are not surprising since we know that younger children are relatively self-centered and have difficulty interacting with others [57]. However, the results also show that an interactive tabletop gives children the possibility to interact naturally, like in a game. The following results are more interesting regarding the 3-4 year-old children, who also experienced the stickers' situation. Both situations were compared for this group ( $c f$. Table 3 ) and supplementary observations - not usable for the older children - were made on error processing. We collected 47 observations for this younger group.

Table 3 Observed relative frequencies - \% - (observed counts) and observed Association Rates (AR) for 34 year-old children's behaviors by situation ("interactive tabletop" or "stickers")

\begin{tabular}{|c|c|c|c|c|c|}
\cline { 2 - 6 } \multicolumn{1}{c|}{ Situation $(\rightarrow)$} & \multicolumn{2}{|c|}{ Stickers } & \multicolumn{2}{c|}{ Interactive tabletop } & \multicolumn{1}{c|}{} \\
\cline { 2 - 6 } \multicolumn{1}{c|}{ Children's behavior $(\downarrow)$} & \% (Counts) & $\boldsymbol{A R}$ & \% (Counts) & $\boldsymbol{A R}$ & Total \\
\hline Interaction & $20.00(2)$ & -0.33 & $80.00(8)$ & +0.14 & $100 \%(10)$ \\
\hline Object manipulation & $36.84(7)$ & +0.24 & $63.16(12)$ & -0.10 & $100 \%(19)$ \\
\hline Error processing & $27.78(5)$ & -0.07 & $72.22(13)$ & +0.03 & $100 \%(18)$ \\
\hline Weighted mean (WM) & \multicolumn{2}{|c|}{$29.79(14)$} & $70.21(33)$ & $100 \%(47)$ \\
\hline
\end{tabular}

\section{Questionnaires}

The three teachers were then asked to complete a set of questionnaires. Each questionnaire had 10 questions for each group of children (One questionnaire was completed for each of the seven groups of children, so seven questionnaires were completed). The teacher answered questions using Likert scales ranging from 1 (strongly disagree) to 10 (strongly agree) and added comments if they so wished. Comments could mention how familiar the children were with the tabletop, how the tabletop changed the behavior of children, how the tabletop appeared to improve the work of children, whether the tabletop was perceived as a computer or a toy, and how appropriate the choices of images and objects and their size were for children.

An initial content analysis showed that, in general, depending on the teacher's perspective, children are very familiar with the tabletop regardless of their age level. However there was a nuance due to the fact that the speakers were removed from the tabletop ${ }^{5}$ : therefore, the younger groups could not immediately associate voice messages with the tabletop (the comment was expressed in a teacher's questionnaire).

Children's behavior changed after using the tabletop, and the teachers reported that younger children (GP1 and GP2) were initially overwhelmed by the tabletop, but they naturally adapted to it.

\footnotetext{
${ }^{5}$ The speakers were removed due to space constraints. The table needed to be integrated into the classroom with minimal movement of furniture and objects.
} 
Regarding the "Does the tabletop appear to improve the work of children" question, the results show that work was not facilitated at first, especially for the youngest children, because a task was considered too easy to perform. For 3-4 year-old children, the teacher's comment was: "Children's use was not facilitated during first time use. I think that with a regular use, work would be facilitated."

According to the teachers who supervise these children, it would be possible that they perceived the tabletop to be more like a toy than a working tool, which is in keeping with the entertaining aspect of the tabletop.

The children had difficulty associating some images, such as (1) the Smurf (cf. Figure 5) and (2) the whale and elephant for the older children, with the color blue, despite the fact that they had worked with all these images before the experiment.

The size of the images was perfectly adapted to all groups (the same image size is commonly used by teachers). The objects were mainly appropriate for the children, but object color was a problem for younger children (each black and white drawing had a red, green, blue or yellow base so that each set of objects could be assigned to a particular child, but this confused some younger children). One teacher suggested using a different identification code for blocks (e.g. stripes or symbols).

In a second phase, a quantitative analysis was conducted by combining the scores given to different questions, (Likert scale from 1 - strongly disagree - to 10 strongly agree -) especially those questions pertaining to behavioral modifications and to interaction facilitation.

Non-parametric statistic Kendall's Coefficient of Concordance (Kendall's $W=0,64$ ) shows that the tree teachers agreed to indicate that the tabletop is a positive support to the children (mean score between 8.5 and 10 for the tree age groups and standard deviation between 0,87 and 1,32) and non-parametric statistic Friedman test confirms that differences between appreciations according the age of children is not significant, as shown figure 14 hereafter.

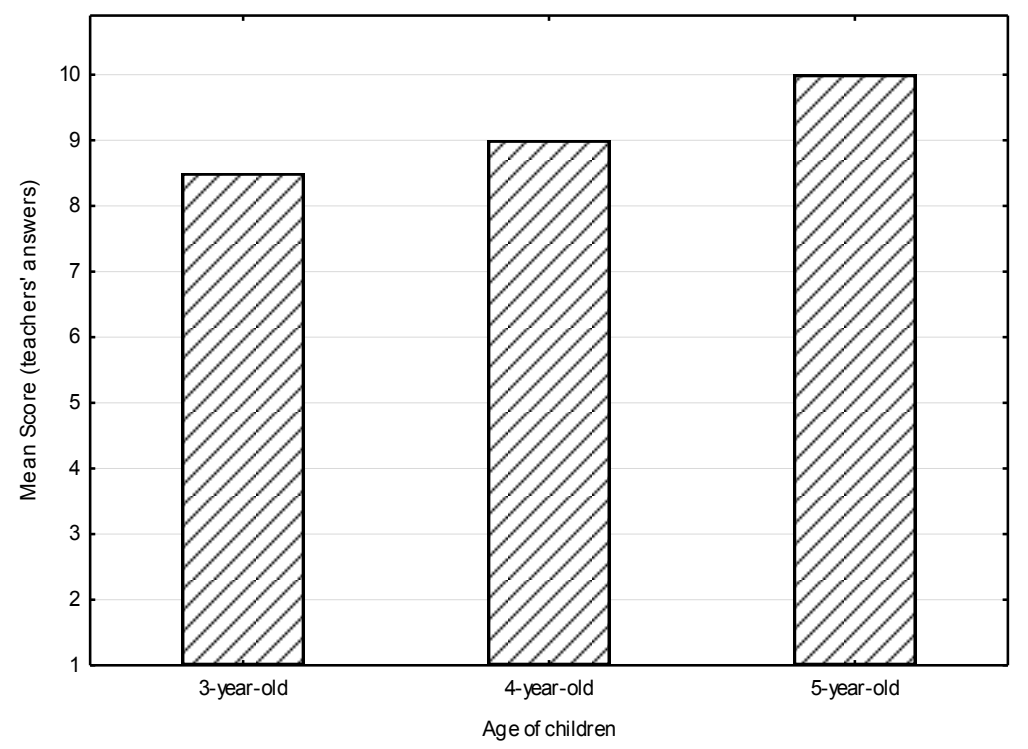

Figure 13 Likert's mean scores derived from answers of teachers according to the behavioral modification and interaction facilitation and according to the children'age)

The three teachers indicated that, for all children, an interactive play system improves and encourages interactions and therefore collective work. For each distribution, the mean score was

\section{Discussion}

The aim of this study was to highlight the contribution of tabletop as support, learning and collaboration aids for young children.

The results from this study indicate: the tabletop attracts the interest of the children and teachers taking part in the experiment. This interest is characterized by more interactions and more errors processing during the use 
of the tabletop specifically for the 4-6 year-old children than when the stickers. The youngest children (3-4 years old), are more interested in manipulating objects. These results are not surprising because children 3 years-old show improved control of crayons or markers, enjoy building with blocks and like manipulate objects, and from 4 years, children begin to cooperate with others, they participate in group activities, they show pride in accomplishments, and they seek frequent adult approval. It is also the beginning of imaginary companions [66].

Even though this study involved relatively few children (16) and was exploratory, it confirms results obtained with other interactive media and other populations of children, notably children with autism [8] and/or specific mental deficiencies [2] [73]: during these studies, the researchers noticed that the involved children tended to interact, verbalize more with respect to demands and concentrate more than with so-called traditional media (e.g. wooden puzzles vs. puzzles on tactile tablets). These new interaction media tend to improve human-human collaboration.

Today, new information technologies are increasingly integrated into educational practices ( $c f$. section 2 ). The learning benefits of such information technologies are currently exploited through digital environments that provide direct access to online resources via dedicated software or the Internet. These new media also facilitate interaction between individuals, learning for children in general, and learning for children with intellectual or cognitive deficiencies in particular [15]. For example, these media can be used to set up a collaborative space, which is a computerized environment whose purpose is to facilitate peer-to-peer collaboration by sharing personal capacities to reach a common goal.

Studies have already been performed to determine the basic principles for designing digital environments to facilitate social interaction [30]; the main observed results show that individuals are more involved in such environments. These authors conclude that, by facilitating social interaction, these new resources may contribute to the development of knowledge and know-how. The same holds true for the elderly, who may also benefit from interactive tablet applications if adapted to their needs [70]. In many countries, laws and application decrees take such aspects into account, leading to the renewal of educational equipment in the educational domain.

These interactive media, which use tangible objects or tactile principles, not only promote interaction, but also provide undeniable educational support; they may stimulate motivation and contribute to reinforcing altered cognitive functions, as proven in a recent study on elderly subjects with Alzheimer's disease [55].

Interaction with tabletop use, in which people use their hands to move different objects or navigate menus, is more natural than traditional interaction using a mouse. Less cognitive and motor effort is required with tabletops involving hand use than indirect pointer tools (such as a mouse) [20][53]. Furthermore, the use of an interactive tabletop promotes tangible interactions, which is intuitive and does not require learning, unlike the use of a keyboard or a mouse [27][17][44]. Finally an interactive tabletop has the advantage of being able to be used by several people at the same time. In contrast, a mouse often stays in the hand of one single user.

Traditional learning methods should not be criticized simply because tactile tablets are used with increasingly frequency. Regardless of the domain, tablets can also have limitations or drawbacks, as mentioned in [13]: the authors state than such new techniques may also distract users from the task at hand. Also, the sense of touch and the perception of natural materials experienced with tangible objects cannot be substituted. For example, for young children, having sticky fingers, touching materials with different textures, and dirtying the hands should remain enjoyable and an integral part of school learning. New interactive technologies therefore should be considered as complementary learning and reinforcement tools. The user-friendliness of these tools still needs to be evaluated; possible approaches were recently proposed [40]. Likewise, new postural constraints may appear with these technologies [10][22][75]. Consequently, a set of studies should be performed on interactive tabletops or tablets to propose answers to such fundamental questions.

A recurrent question pertains to whether such studies should be performed in the laboratory or in the field [32]. Our field study on very young children, for which an authorization was obtained for one day only, revealed several practical aspects. The tables need to be made comfortable for children to use:

- The tabletop was placed in their usual environment, near their regularly-used tables (cf. Figure 9). The tabletop was adjusted to the same height as the other school tables so that the children could work in their usual fashion. 
- Furthermore, the interactive tabletop exercises were integrated into the exercises of the daily educational program for each of the groups by respecting the children's (rituals) and their associated schedule.

- Finally only the teacher provided children with necessary explanations. First the analysts provided the teachers with all the information they needed to help pupils make progress on the exercises before the teachers explained things to the children. It was important for the analysts to be discreet during the exercises; the analysts behaved like auxiliary school staff, making it easy for children accustomed to having different kinds of people (auxiliary staff, trainees) in the classroom all year long to adapt to their presence.

It would be interesting to set up other studies with very young children: it would be possible to replicate the conditions or to use variants of the task (for instance: exercises about categorization as presented for children with autism [73] because this cognitive ability is a key for learning, as it allows information to be processed more quickly and more efficiently. It allows also dealing with concepts and organizing the environment [56]. It also seems important to continue to perform such studies in classrooms so that children can stay in their usual context.

In future studies, video recordings would help describe postures, which would be helpful in terms of identifying any movement constraints and possible support points [6][7] to make sure that this new interactive mode does not induce postural or gestural problems [64].

\section{Conclusion}

The constant evolution of information technology has enabled new interactive educational media to be designed. Interactive tabletops and their hardware, software and methodology are currently the subject of numerous studies. In this article, we focused on the use of interactive tabletops by children in an educational setting. An interactive application dedicated to children aged 2 to 5 years was identified and developed in collaboration with schoolteachers.

Playing with a tabletop can help children learning and recognizing four basic colors (red, blue, yellow, green). In addition, New Information and Communication Technologies (NICT) are becoming increasingly incorporated into educational practices, stimulate exchange between individuals, and motivate teachers. This new type of interactive application runs on an interactive tabletop equipped with RFID technology. It enables users to manipulate virtual and tangible objects. Written in JAVA, this application is based on the JADE multi-agent platform described in this article. It was used for an exploratory field study in a preschool. Several groups of children aged 3 to 5 years were involved in the study. They were asked to participate in an exercise in a collective context (children + teacher group) on an interactive tabletop in their classroom. The youngest children also performed the exercise on paper (the exercise is one that has been used in preschools for decades). The interactive tabletop exercise interactions were filmed. The teacher completed a questionnaire for each group of children. The data analysis indicates promising results.

The children easily understood the application, since such edutainment enables choices to be questioned and errors to be corrected more easily than the paper version of the exercise. The exercise was performed in a collective context, facilitating interactions between children and their teacher. The study detected more interaction in older children (4-5 and 5-6 year-olds) than in the youngest children (3-4 year-olds) and this is in line with cognitive development of children. This research paves the way for numerous future studies. It would be interesting to perform as many other field studies as possible, with different categories of children, such as children experiencing and not experiencing educational underachievement and children with and without intellectual deficiencies (such as infantile autism, which is currently the subject of numerous healthcare studies). Different application variants may be employed: number learning, alphabet learning and so on. A more general research question would be the following: How can interactive tabletops be used to reinforce learning in situations that are difficult or impossible with traditional methods? Finally, it should be noted several interactive tabletop applications are currently be studied or developed. 


\section{Acknowledgements}

This research was partially financed by the French Ministry of Education, Research \& Technology, the Nord/Pas-de-Calais Region, the French National Center for Scientific Research (CNRS), the FEDER program, the International Campus on Safety and Intermodality in Transportation (the Plaiimob project) and the French National Research Agency (ANR TTT and IMAGIT projects, financial IMAGIT support: ANR-10-CORD-017). The authors would like to thank the partners with whom we collaborated on the TTT and IMAGIT projects: LIG, RFIdées and the CEA. We would also like to thank the Inspector of Education, Mrs. Thery, Mrs. Petit, Mrs. Grechez and Miss Dudkowiak for their assistance given for the development and evaluation of the application, and also the parents and all of the children at the school in Caullery (F-59191).

\section{References}

[1] Alibali M. W., diRusso A. A. (1999). The function of gesture in learning to count: More than keeping track. Cognitive Development, Vol. 14, p. 37-56.

[2] Amar, D., Goléa, M.,Wolff, M., Gattegno, M., Adrien, J.-L., 2012. Apports des tablettes tactiles pour jeunes adultes présentant une déficience mentale ou un trouble autistique : études de cas. In: 24th French Speaking Conference on Human-Computer Interaction. Ergo'IHM 2012. ACM, New York, NY, USA, pp. 3-6.

[3] Ampofo-Boateng, K., Thomson, J. A., Grieve, R., Pitcainr, T., Lee, D. N., Demetre, J. D., 1993. A developmental and training study of children's ability to find safe routes to cross the road. British Journal of Developmental Psychology 11 (1), 31-45.

[4] Arfib, D., Filatriau, J.-J., Kessous, L., 2009. Prototyping musical experiments for TangiSense, tangible and tracable table. In: Sound and Music conference (SMC'09). Porto, Portugal, pp. 258-263.

[5] Bakker, S., Antle, A., van den Hoven, E., 2012. Embodied metaphors in tangible interaction design. Personal and Ubiquitous Computing 16, 433-449, 10.1007/s00779-011-0410-4.

[6] Barbé, J., Chatrenet, N., Mollard, R., Bérard, P., Wolff, M., 2012. Physical ergonomics approach for touch screen interaction in an aircraft cockpit. In: 24th French Speaking Conference on Human-Computer Interaction. Ergo'IHM 2012. ACM, New York, NY, USA, pp. 12-19.

[7] Barbé, J., Wolff, M., Mollard, R., 2013. Human centred design approach to integrate touch screen in future aircraft cockpits. In: Proceedings of the HCI International 2013. LNCS. ACM, New York, NY, USA, p. to appear.

[8] Battocchi, A., Gal, E., Ben Sasson, A., Pianesi, F., Venuti, P., Zancanaro, M., Weiss, P. L., Kessler, B., 2008. Collaborative puzzle game - an interface for studying collaboration and social interaction for children who are typically developed or who have autism spectrum disorder. In: 7th ICDVRAT with ArtAbilitation. ICDVRAT/University of Reading, UK, pp. 127-134.

[9] Bellifemine, F., Poggi, A., Rimassa, G., 2001. Developing multi-agent systems with a FIPA-compliant agent framework. Software: Practice and Experience 31 (2), 103-128.

[10] Benford, S., Schnadelbach, H., Koleva, B., Gaver, B., Schmidt, A., Boucher, A., Steed, A., Anastasi, R., Greenhalgh, C., Rodden, T., Gellersen, H., 2003. Sensable and Desirable: a Framework for Designing Physical Interfaces. Tech. rep., University College London.

[11]Bernard, J. M., 2003. Analysis of Local or Asymmetric Dependencies in Contingency Tables using the Imprecise Dirichlet Model. In: Zaffalon (Ed.), ISIPTA'03: Proceedings of the 3rd International Symposium on Imprecise Probabilities their Applications. Vol. 18. Switzerland, pp. 46-61.

[12] Bonnard Q., Jermann P., Legge A., Kaplan F., Dillenbourg P. (2012). Tangible paper interfaces: interpreting pupils' manipulations. In Proceedings of the 2012 ACM international conference on Interactive tabletops and surfaces (ITS '12), New York, NY, USA, p. 133-142.

[13] Buisine, S., Besacier, G., Najm, M., Aoussat, A., Vernier, F., 2007. Computer-Supported Creativity: Evaluation of a Tabletop Mind-Map Application. In: Harris, D. (Ed.), HCII '07: Engineering Psychology 
and Cognitive Ergonomics. Lecture Notes in Computer Science, Springer-Verlag Berlin Heidelberg, Beijing, P.R. China, pp. 22-31.

[14] Burnett A. (1962). Montessori Education Today and Yesterday. The Elementary School Journal, Vol. 63(2), p. 71-77.

[15] Chalghoumi, H., Kalubi, J.-C., Rocque, S., 2008. Les technologies de l'information et de la communication dans l'éducation des élèves qui ont des incapacités intellectuelles : rôle des perceptions, de la formation, et du niveau de qualification des enseignants en adaptation scolaire. Revue Francophone de la déficience Intellectuelle 19, 72-79.

[16] Clay, A., Wolff, M., Mollard, R. (2014). User-designed movement interactions: an exploratory study for natural interactions. European Journal of Automation (EJA), 4-5-6, 453-472.

[17] Cohé, A., Dècle, F., Hachet, M., 2011. tbox: a 3d transformation widget designed for touch-screens. In: Proceedings of the SIGCHI Conference on Human Factors in Computing Systems. CHI '11. ACM, New York, NY, USA, pp. 3005-3008. URL http://doi.acm.org/10.1145/1978942.1979387

[18] Corroyer, D., Marion, 2003. L’analyse statistique des données pour la Psychologie : concepts et méthodes de base. Armand Colin.

[19] Darses, F., Wolff, M., 2006. How do designers represent to themselves the users' needs? Applied Ergonomics 37 (6), 757-764.

[20]Decle F. (2009). Approches directes et planifiées de l'interaction 3D sur terminaux mobiles (Thèse $n^{\circ}$ d'ordre : 3836). École doctorale de mathématiques et d'informatique, Université Bordeaux 1, France.

[21]Do-Lenh, S., Kaplan, F., Dillenbourg, P., 2009. Paper-based concept map: the effects of tabletop on an expressive collaborative learning task. In: BCS-HCI '09: Proceedings of the 23rd British HCI Group Annual Conference on People and Computers: Celebrating People and Technology. British Computer Society, Swinton, UK, UK, pp. 149-158.

[22]Fiebrink, R., Morris, D., Morris, M. R., 2009. Dynamic mapping of physical controls for tabletop groupware. In: CHI '09: 27th international conference on Human factors in computing systems. ACM, New York, NY, USA, pp. 471-480.

[23] Finkenzeller, K., 2003. RFID Handbook: Fundamentals and Applications in Contactless Smart Cards and Identification. John Wiley \& Sons, Inc., New York, NY, USA.

[24] Fishkin, Kenneth P., 2004. A taxonomy for and analysis of tangible interfaces. Personal and Ubiquitous Computing. 8(5) pp. 347-358.

[25]Fyhri, A., Bjornskau, T., Ulleberg, P., 2004. Traffic education for children with a tabletop model. Transportation Research Part F: Traffic Psychology and behaviour 7 (4-5), 197 - 207.

[26] Glover, D., Miller, D., Averis, D., Door, V., 2005. The interactive whiteboard: a literature survey. Technology, Pedagogy and Education 14 (2), 155-170.

[27] Hachet, M., Decle, F., Knödel, S., Guitton, P., 2009. Navidget for 3d interaction: Camera positioning and further uses. Int. J. Hum.-Comput. Stud. 67 (3), 225-236.

[28] Harris A., Rick J., Bonnett V., Yuill N., Fleck R., Marshall P., Rogers Y. (2009). Around the table: are multiple-touch surfaces better than single-touch for children's collaborative interactions? In Proceedings of the 9th international conference on Computer supported collaborative learning (CSCL'09), Claire O'Malley, Daniel Suthers, Peter Reimann, and Angelique Dimitracopoulou (Eds.), Vol. 1, International Society of the Learning Sciences, p. 335-344.

[29] Hays, W. L., 1994. Statistics. Fort Worth, TX: Harcourt Brace College Publishers.

[30] Hernández-Serrano, M., González-Sanchez, M., Munoz-Rodríguez, J., 2009. Designing learning environments improving social interactions: essential variables for a virtual training space. Procedia - Social and Behavioral Sciences 1 (1), $2411-2415$. 
[31] Higgins S., Mercier E., Burd E., Hatch A. (2011). Multi-touch tables and the relationship with collaborative classroom pedagogies: A synthetic review. In International Journal of Computer-Supported Collaborative Learning, Vol. 6(4), p. 515-538

[32] Hoc, J.-M., 2001. Towards ecological validity of research in cognitive ergonomics. Theoretical Issues in Ergonomics Science 2 (3), 278-288.

[33] Hodge, S., Anderson, B., 2007. Teaching and learning with an interactive whiteboard: a teacher's journey. Learning, Media and Technology 32 (3), 271-282.

[34] Horn, M. S., Crouser, R. J., Bers, M. U., 2012. Tangible interaction and learning: the case for a hybrid approach. Personal Ubiquitous Computing 16 (4), 379-389.

[35] Ishii H (2008) Tangible bits: beyond pixels. In: Proceedings of the 2nd international conference on tangible nd embedded interaction, New York, NY, USA, pp xv-xxv

[36] Ishii H, Ullmer B (1997) Tangible bits: towards seamless interfaces between people, bits and atoms

[37] Kelly A. R., Wallace J. R., Cerar K., Randall N., McClelland P., Mindy Seto A. (2010). Solar scramble: an educational children's game for collaborative multi-touch digital tabletops. In Proceedings of the 28th ACM International Conference on Design of Communication (SIGDOC '10). ACM Press, New York, NY, USA, p. 27-32

[38] Kennewell, S., Tanner, H., Jones, S., Beauchamp, G., 2008. Analysing the use of interactive technology to implement interactive teaching. Journal of Computer Assisted Learning 24 (1), 61-73.

[39] Kruger, R., Carpendale, S., Scott, S. D., Greenberg, S., 2003. How people use orientation on tables: comprehension, coordination and communication. In: GROUP '03: Proceedings of the 2003 international ACM SIGGROUP conference on Supporting group work. ACM Press, pp. 369-378.

[40] Kubicki, S., Borgiel, K., Lepreux, S., Wolff, M., Kolski, C., 2012. Réflexions autour des tables interactives : expérience utilisateur, utilisabilité, évaluation. Le travail humain 3/2012 (Vol. 75), 229-252.

[41] Kubicki, S., Lebrun, Y., Lepreux, S., Adam, E., Kolski, C., Mandiau, R., 2013. Simulation in contexts involving an interactive table and tangible objects. Simulation Modelling Practice and Theory $31(0), 116-$ 131.

[42] Kubicki, S., Lepreux, S., Kolski, C., 2011. Evaluation of an interactive table with tangible objects: Application with children in a classroom, 2nd Workshop on Child Computer Interaction "UI Technologies and Educational Pedagogy", at CHI'2011.

[43] Kubicki, S., Lepreux, S., Lebrun, Y., Santos, P. D., Kolski, C., Caelen, J., 2009. New Human-Computer Interactions Using Tangible Objects: Application on a Digital Tabletop with RFID Technology. In: Jacko, J. A. (Ed.), Human-Computer Interaction. LNCS 5612. Springer, pp. 446-455.

[44] Laviole, J., Hachet, M., march 2012. Papart: Interactive 3d graphics and multi-touch augmented paper for artistic creation. In: 3D User Interfaces (3DUI), 2012 IEEE Symposium on. pp. 3 -6.

[45] Le Roux, B., Rouanet, H., 2004. Geometric data analysis: from correspondence analysis to structured data analysis. Bruxelles: Kluwer.

[46]Lebrun, Y., Adam, E., Kubicki, S., Mandiau, R., 2010. A Multi-Agent System Approach for Interactive Table Using RFID. In: PAAMS 2010, 8th International Conference on Practical Applications of Agents and Multiagent Systems. Vol. 70. Salamanca, Spain, pp. 125-134.

[47] Lucchi, A., Jermann, P., Zufferey, G., Dillenbourg, P., 2010. An empirical evaluation of touch and tangible interfaces for tabletop displays. In: TEI '10: Proceedings of the fourth international conference on Tangible, embedded, and embodied interaction. ACM Press, pp. 177-184.

[48] Manches, A., O’Malley, C., 2012. Tangibles for learning: a representational analysis of physical manipulation. Personal and Ubiquitous Computing 16, 405-419, 10.1007/s00779-011-0406-0.

[49] Marco, J., Cerezo, E., Baldassarri, S. 2013. Bringing tabletop technology to all: evaluating a tangible farm game with kindergarten and special needs children. Personal and Ubiquitous Computing 17(8): 1577-1591. 
[50] Marshall, P., 2007. Do tangible interfaces enhance learning? In: TEI '07: Proceedings of the 1st international conference on Tangible and embedded interaction. ACM Press, pp. 163-170.

[51] Martin, P. E., 2000. Pupitre du 21ème siècle pour la classe du 21ème siècle. Revue de l'Enseignement Public et Informatique 97, 89-98.

[52] Martínez, R., Collins, A., Kay, J., Yacef, K., 2011. Who did what? Who said that?: Collaid: an environment for capturing traces of collaborative learning at the tabletop. In: ITS'11: Proceedings of the ACM International Conference on Interactive Tabletops and Surfaces. ACM Press, pp. 172-181.

[53] Mertz, C., \& Vinot, G.L. (1999). Touch input screens and animations: more efficient and humanized computer interactions for ATC(O). In Proceedings 10th International Symposium on Aviation Psychology (pp. 615-621). Columbus, Ohio.

[54] Piper, A. M., Hollan, J. D., 2009. Tabletop displays for small group study: affordances of paper and digital materials. In: CHI '09: Proceedings of the 27th international conference on Human factors in computing systems. ACM Press, pp. 1227-1236.

[55] Plos, O., Buisine, S., Aoussat, A., Mantelet, F., Dumas, C., 2012. A universalist strategy for the design of assistive technology. International Journal of Industrial Ergonomics 42 (6), 533 - 541.

[56] Rosch E. (1973). Cognitive Reference Points. Cognitive Psychology, 7, 532-547.

[57] Rubin, K. H., Coplan, R. J., Nelson, L. J., Cheah, C. S. L., Lagace-Seguin, D. G., 1999. Peer relationships in childhood. Hillsdale, NJ: Erlbaum., Ch. Developmental Psychology: An advanced textbook, 4th Edition, pp. 451-502.

[58] Sapounidis, T., Demetriadis, Stavros N. (2013) Tangible versus graphical user interfaces for robot programming: exploring cross-age children's preferences. Personal and Ubiquitous Computing 17(8): 17751786

[59] Shaer, O., Strait, M., Valdes, C., Wang, H., Feng, T., Lintz, M., Ferreirae, M., Grote, C., Tempel, K., Liu, S., October 2012. The design, development, and deployment of a tabletop interface for collaborative exploration of genomic data. International Journal of Human-Computer Studies 70 (10), 746-764.

[60] Shaer, O., Valdes, C., Liu, S., Lu, K., Chang, K., Xu., Haddock, T., Bhatia, S., Densmore, D., Kincaid. R. (2014). Designing reality-based interfaces for experiential bio-design. Personal and Ubiquitous Computing 18(6): 1515-1532

[61] Sluis, R. J. W., Weevers, I., van Schijndel, C. H. G. J., Kolos-Mazuryk, L., Fitrianie, S., Martens, J. B. O. S., 2004. Read-It: five-to-sevenyear-old children learn to read in a tabletop environment. In: IDC '04: Proceedings of the 2004 conference on Interaction design and children: building a community. ACM Press, pp. 73-80.

[62] Sommer, R., Sommer, B., 1980. A practical guide to behavioral research: tools and techniques. Oxford University Press.

[63] Soute, I., Kaptein, M., Markopoulos, P., 2009. Evaluating outdoor play for children: virtual vs. tangible game objects in pervasive games. In: Proceedings of the 8th International Conference on Interaction Design and Children. IDC '09. ACM, New York, NY, USA, pp. 250-253.

[64] Straker, L., Coleman, J., Skoss, R., Maslen, B., Burgess-Limerich, R., Ploock, C., 2008. A comparison of posture and muscle activity during tablet computer, desktop computer and paper use by young children. Ergonomics 51, 540-555.

[65] Sylla, C., Branco, P., Coutinho, C., Coquet, E., 2012. TUIs vs. GUIs: comparing the learning potential with preschoolers. Personal and Ubiquitous Computing 16, 421-432, 10.1007/s00779-011-0407-z.

[66] Taylor, M., Carlson, S.M., Maring, B.L., Gerow, L., \& Charley, C.M. (2004). The characteristics and correlates of fantasy in school-age children: imaginary companions, impersonation, and social understanding. Development Psychology, 40, 6, 1173-1187. 
[67] Thomson, J. A., Ampofo-Boateng, K., Pitcairn, T. K., Grieve, R., Lee, D. N., Demetre, J. D., 1992. Behavioral group training of children to find safe routes to cross the road. British Journal of Educational Psychology 62, 173-183.

[68] Tse, E., Schöning, J., Huber, J., Marentette, L., Beckwith, R., Rogers, Y., Mühlhäuser, M., 2011. Child computer interaction: 2 nd workshop on UI technologies and educational pedagogy. In: CHI EA '11: 29th of the international conference extended abstracts on Human factors in computing systems. pp. 2445-2448.

[69] Tse, E., Schöning, J., Rogers, Y., Shen, C., Morrison, G., 2010. Next generation of HCI and education: Workshop on UI technologies and educational pedagogy. In: CHI EA '10: 28th of the international conference extended abstracts on Human factors in computing systems. pp. 4509-4512.

[70] Vandi, C., Rico Duarte, L., Tijus, C., 2011. Livre blanc : Séniors et tablettes interactives.

[71] Wendland, J., Maggi, A., Wolff, M., 2010. Maternal strategies for regulating their children's behavior in brazilian mothers of german and italian descent. Revista Interamericana de Psicología / Interamerican Journal of Psychology 44 (1), 1-11.

[72] Wolff, M., 2003. Apports de l'analyse géométrique des données pour l'analyse de l'activité. Paris : PUF, Ch. Formalismes de modélisation pour l'analyse du travail et l'ergonomie, pp. 195-227.

[73] Wolff, M., Gattegno, M.P., Adrien, J.-L., Gabeau, C., \& Isnard, P. (2014). Contribution of tablets to the support of children and adolescents with autistic disorders. European Journal of Automation (EJA), 4-5-6, 261-282 .

[74] Xie, L., Antle, A. N., Motamedi, N., 2008. Are tangibles more fun?: comparing children's enjoyment and engagement using physical, graphical and tangible user interfaces. In: TEI '08: Proceedings of the 2nd international conference on Tangible and embedded interaction. ACM Press, pp. 191-198.

[75] Young, J. G., Trudeau, M., Odell, D., Marinelli, K., Dennerlein, J. T., 2012. Touch-screen tablet user configurations and case-supported tilt affect head and neck flexion angles. Work: A Journal of Prevention, Assessment and Rehabilitation 41, 81-91.

[76]Zaman, B., Vanden-Abeele, V., Markopoulos, P., Marshall P. (2012). Editorial: the evolving field of tangible interaction for children: the challenge of empirical validation. Personal and Ubiquitous Computing 16(4): 367-378.

[77]Zuckerman O., Gal-Oz A. (2013). To TUI or not to TUI: Evaluating performance and preference in tangible vs. graphical user interfaces, International Journal of Human-Computer Studies, Volume 71, Issues 7-8, July-August 2013, Pages 803-820, ISSN 1071-5819.

[78]Zuckerman, O., Arida, S., Resnick, M., 2005. Extending tangible interfaces for education: digital montessori-inspired manipulatives. In: Proceedings of the SIGCHI conference on Human factors in computing systems. CHI '05. ACM, New York, NY, USA, pp. 859-868. 